Article

\title{
Design Specifications for an Auxiliary Incision Retractor in Dacryocystorhinostomy Surgeries
}

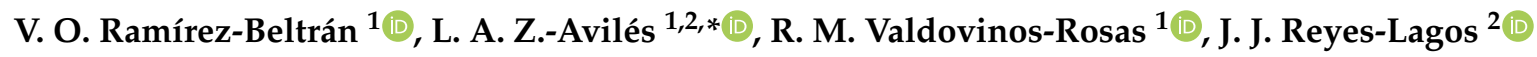 \\ and G. M. Cruz-Martínez ${ }^{1}$ (D) \\ 1 Faculty of Engineering, Autonomous University of Mexican State, Cerro de Coatepec Street, Universidad, \\ Toluca de Lerdo 50130, Mexico; rhcpsm@hotmail.com (V.O.R.-B.); li_rmvr@hotmail.com (R.M.V.-R.); \\ gmcruzm@uaemex.mx (G.M.C.-M.) \\ 2 Faculty of Medicine, Autonomous University of Mexican State, Tollocan Avenue, \\ Ciprés, Toluca de Lerdo 50120, Mexico; jjreyesl@uaemex.mx \\ * Correspondence: lazunigaa@uaemex.mx; Tel.: +52-722-214-08-55 or +52-551-201-8024 (ext. 1204)
}

Received: 22 November 2019; Accepted: 23 December 2019; Published: 14 January 2020

check for updates

\begin{abstract}
It is presented the design specifications for a Retractor Robotic System (RRS) based on the surgical necessities in the incisions procedure for a dacryocystorhinostomy. The specifications are conformed by a mathematical model, the experimental data measured, a modular flexible architecture, energy supplier system, the mechanical group, and the safety system. The specifications suggest that the use of flexible polymeric materials for the RRS provide a mayor adaptability of the system with the biological tissue; so a pneumatic actuator could be a suitable option.
\end{abstract}

Keywords: dacryocystorhinostomy; incisions retraction; retractor robotic system; design specifications; stress tensor

\section{Introduction}

A dacriocistorrynostomy (DCR) is an ocular surgery that removes the obstruction on the nasal lacrimal, allowing a normal draining to the nasal cavity trough a new drainage via [1,2]. The DCR is the most common surgical technique in lacrimal blockage in cases of chronic dacryocystitis and nasolacrimal duct [1-3]. General Hospital of Mexico City estimates that, from 2000 to 2007, 222 dacricistitys cases were diagnosed, and 194 of those were treated by a type of DCR $[4,5]$.

During a DCR, an incision between the ocular cavity and the nasal apparatus is performed [1,6,7]. The incision consists on a tangential cut of $2-4 \mathrm{~cm}$ of length and its complemented by scissors to get inside to the nasal bone $[6,8,9]$. Once the incision depth is achieved, it is open by the use of manual retractors until the lacrimal sac is founded $[8,10]$.

Table 1 shows principal instruments used in the stage of retraction incision in a DCR. The retraction, identification, exposure of tissues, and skin are crucial steps in a DCR that allow for a workspace and mobility needed by the surgeon $[9,10]$.

Table 1. Instruments for a incision retraction in a dacriocistorrynostomy [7].

\begin{tabular}{ccc}
\hline & Instruments & \\
\hline Anesthesia & Vaso-builder spray & Antiseptic \\
Cold scalpel & Scissors & Retractors \\
Curved mosquito & Wescott scissors & Silicone tubes \\
\hline
\end{tabular}

A DCR is considered safe, with low aesthetic repercussions and a high rate of success $[1,2,11]$. The effectiveness rate of a DCR is $85 \%$, but the group valuation shows $71 \%$ effectiveness in DCR in 
both eyes $[4,7,12]$. The problems are related with the workspace $(\simeq 2 \mathrm{~cm})$ in which It is necessary to liberate a minimum area to introduce the instruments in Table $1[4,8]$. In this process, the surgeon requires assistance of other surgeons for the incision retraction, the tissue manipulation, and the incision drainage. The incision retraction is the longest process in a DCR.

Given the anatomical differences of each patient, It is required that both the surgeon and the assistant must have knowledge in canalicular pathologies, the use of medical tools, and a high level of skills for manipulation of tissues and skin in reduced spaces [2]. The most common complications are bleeding and a broken nasal flap, which generate complications for the patient and the specialist [13].

A DCR needs the availability of 3-5 expert surgeons on lacrimal surgery for a single procedure [7]. These needs increase costs, surgery time and risk for the patient [4]. This problem generates a need to develop a Robotic Retraction System (RRS), which retracts the incision automatically, assists with problems of the workspace for the incision and therefore reduces the number of specialists required.

The construction and design of an RRS start on the determination of the mechanical skin behavior during the stage of manipulation and retraction of the incision in a DCR. This behavior generates the design specifications for a RRS. The theoretical and experimental results of forces, pressures, deformations, tensions, and workspace area derived from the opening of incisions in a DCR are presented in this article. These results are considered the design specifications needed in the construction of a incision retractor, and it was recollected in an experimental form with the reproduction of the skin retraction of a pig's head's measuring forces of lengths simulating a typical dacriocistorrynostomy $[14,15]$.

The experimental information allows for developing a mathematical model that replicates the incisions' interactions and behavior during its manipulation in a surgery $[16,17]$. The incision replication presented is based on the mechanical characteristics of the multilayer composite of skin.

The geometrical incision behavior is related to the opening points. In a DCR, the opening points are limited with the workspace and the minimum retraction points needed for a homogeneous workspace area are three. The skin can be viewed as a multi-layer shell structure with non-negligible bending stiffness $[15,18]$. It contains fibers contributing to the tensile mechanical properties of the skin and leads to anisotropic and nonlinear macroscopic mechanical properties observed in biological soft tissues under tension [18]. The mechanical behavior of skin can be considered as an anisotropic tissue in the structural characteristics and its layers correlated with the Langer lines $[14,15,18]$. On a 3D structure, the skin has distinct mechanical properties [18].

A variety of methods have been used to measure the mechanical properties of skin and those consider nonlinear behavior, structural non-homogeneity, and mechanical anisotropy, but this is not developed in the skin incision retraction $[18,19]$. The external forces applied at the incision could be considered similar to the tensions in the skin without any cut; therefore, this mathematical model will consider the same tensor behavior [20].

The external forces applied at the skin will be obtained experimentally relating the force applied with the skin length retracted in time. Due to difficulties of measuring human skin on the ocular zone, it is necessary to replicate the mechanical behavior with tissue surrogates [18].

Rat and pig animal skin has been the most common replacement for human skin and the pig skin has been shown to be a suitable mechanical properties(Young's Modulus) for human skin $[14,15,18]$. In order to simplify the problem, the incision is considered an underlying material that suffers stress as there is a continuous disregard for its molecular structure; this is called the mechanics of a continuous medium. This type of mechanics can relate stresses and deformations with lengths and forces [20-22].

The stress vector can be simplified into two components: the normal component $\left(\sigma_{n}=t \cdot \hat{n}\right)$ and tangential plane $\left(\tau_{n}^{2}=t^{2}-\sigma_{n}^{2}\right)$. The Mohr's circle is a geometrical representation of solid stresses subdued by external forces [21].

Another graphic representation on a tensor is called the Lamé ellipse, which relates the stress tensor into an ellipse. In a Lamé ellipse, the stress tensor has a canonic form and the main stress comes in the diagonal matrix $\left(\sigma_{i}\right)$ with the points outside the diagonal being null [20,22]. These graphic 
methods will be used for the mathematical modeling in the incision retraction process. The retraction points could have an opening radio similar to a Mohr's circle [21]. The three retraction points expand geometrically similar to a Lamé ellipse [21]. Figure 1 shows the incision geometrical behavior in the retraction process.

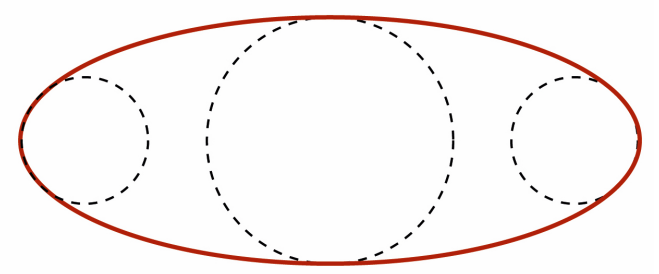

Figure 1. Incision behavior in the points retraction process. each retraction point represent Mohr's circle, but together the points replicate a Lamé ellipse.

The mathematical model gives the design parameters needed for the design of an RRS. In sections are presented as follows: the design specifications for the construction of a retractor, the mathematical model, and the theoretical and experimental validations in the opening of the incisions in the orbital cavity of a pig's head.

\section{Methodology}

In the present work, the methodology is divided into three stages, the retraction points generating the technical criteria's for the process; the geometrical behavior to have an homogeneous workspace area and the case study simplifying the mathematical model. With the considerations and parameters defined, the methodology continues the validation in order to find an experimental and theoretical validation of the opening retraction process. All the stages are shown in Figure 2 and developed in the following sections.

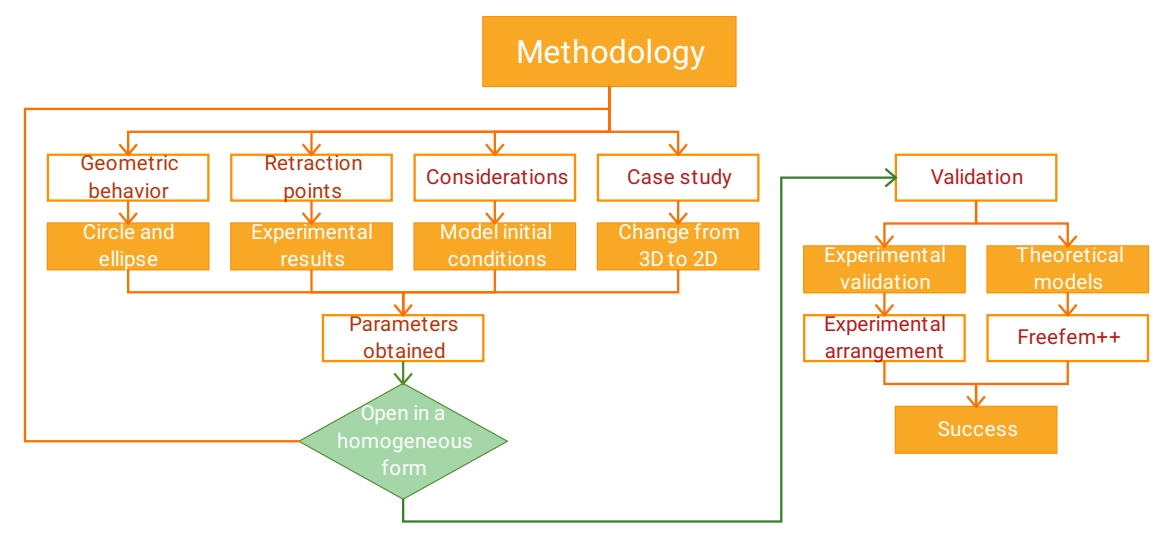

Figure 2. Methodology defined to design specifications for an robotic retractor system.

\subsection{Retraction Points}

In a DCR, a tangential incision cut the skin at different depths. Once the cut is made, the incision is retracted and the workspace is liberated. This process continues until all the tissues and skin are removed and the surgeon has free access to the nasal bone. 


\subsubsection{Instruments}

This work replicates the incision process using as tissue a pig's skin located in the ocular cavity due to having similar characteristics to the human head [14]. Table 2 shows the features of the pig's head used.

Table 2. Dimensions, weights, and sample's age.

\begin{tabular}{cc}
\hline \multicolumn{2}{c}{ Characteristics } \\
\hline Animal part & Pig's head \\
Age & 6 months \\
Animal's weight & $92 \mathrm{~kg}$ \\
Head's weight & $2.1 \mathrm{~kg}$ \\
& Long: 500 \\
Dimensions (mm) & Width: 130 \\
& High: 120 \\
TIF certification & Yes \\
\hline
\end{tabular}

For the surgery replication, the target of the instruments selected was to keep the same conditions of an incision being opening during time as in a DCR. The measures were performed with the instruments in Table 3.

Table 3. Instruments for the measurement process.

\begin{tabular}{lcl}
\hline Instrument & Amount & Characteristics \\
\hline Digital dynamometer & 1 & PASCO Scientific CI-6537 force sensor \\
Analog Vernier & 2 & Metromex 333-P plastic range of $5 \mathrm{~mm}$ \\
Light & 1 & TEKCOPLUS DSTK-110 \\
Universal support & 3 & Dipstick size 600 mm y Base size $(200 \times 140) \mathrm{mm}$ \\
Scalpel & 1 & Zamsa model zs-05-1105 \\
\hline
\end{tabular}

\subsubsection{Procedure}

The measurement procedure was divided into two stages that begin with the sample assembly and the data acquisition. Figure 3 shows the protocol flowchart.

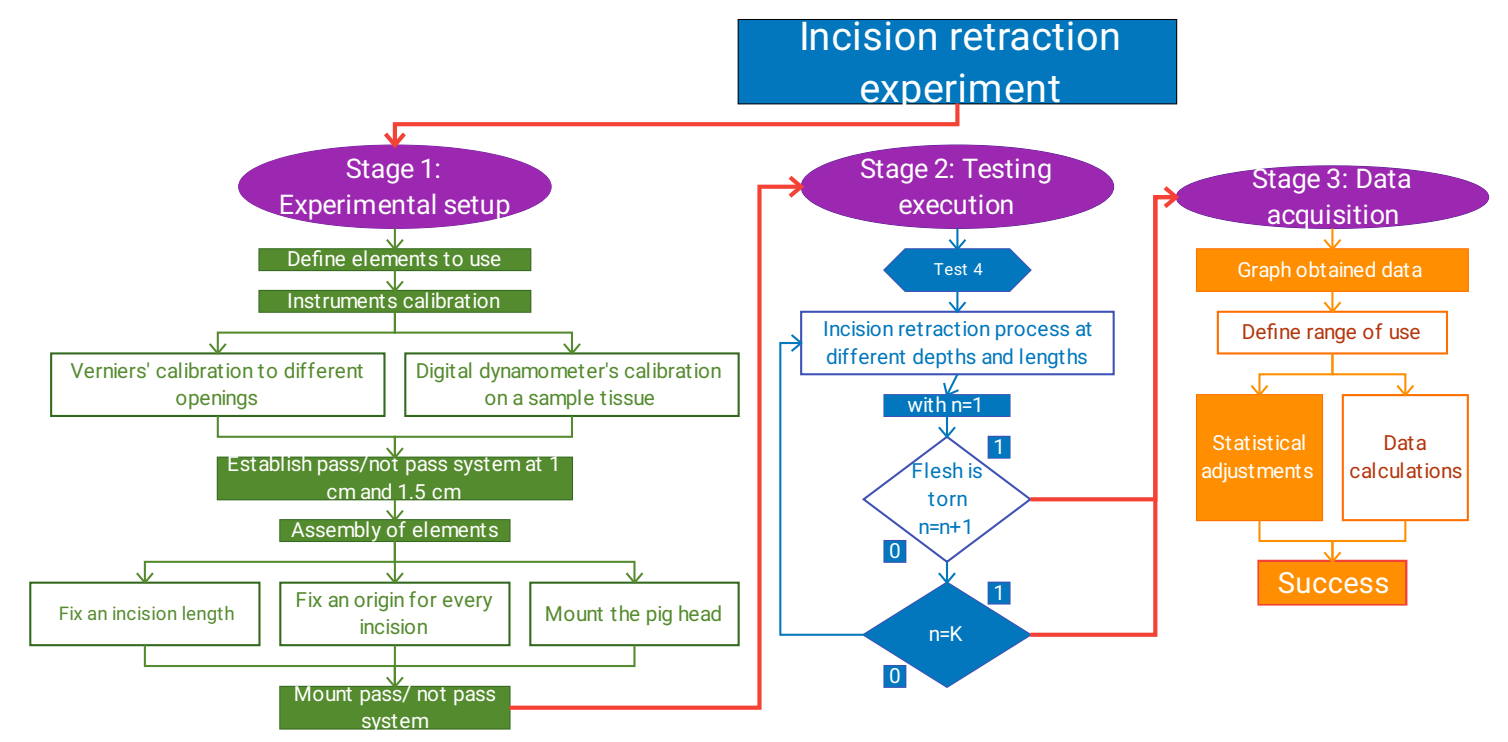

Figure 3. Experimental protocol. 
The incisions were retracted by a hook from an origin and moving through a coordinate axis. The incision retraction had four different parameters in width $(1 \mathrm{~cm}$ and $1.5 \mathrm{~cm})$ and depth $(2 \mathrm{~mm}$ and $4 \mathrm{~mm}$ ). This process has as a purpose to measure the necessary forces to keep open the incision at desired widths. The forces were measured with a digital dynamometer which transmitted the signal into an interface for the forces plot at a defined time $(0.5 \mathrm{~s})$. The graph measured is shown in Figure 4 .

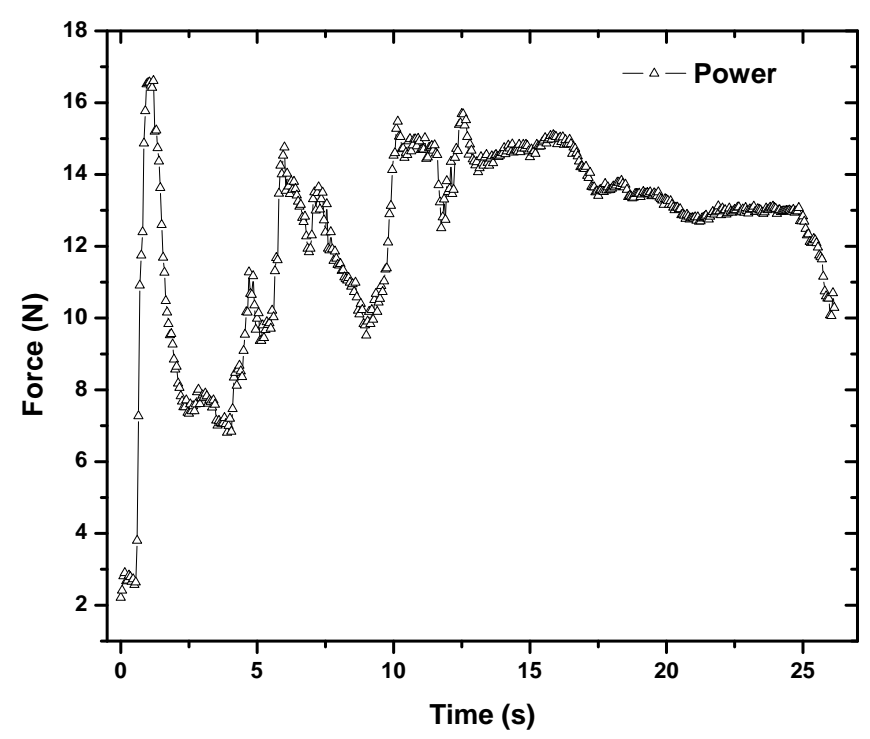

Figure 4. Forces measured during the entire incision opening process.

Figure 4 presents the incision retraction process from the retraction start and the end of it. The data obtained in Figure 4 has been re-adapted into a new sample space and the new interval was set from $13 \mathrm{~s}$ to $14 \mathrm{~s}$. This sample space was defined to remove the inconsistencies generated for the forces applied. This procedure allows for measuring the forces needed to generate opening points at determined lengths. The punctual lengths give quasi-linear information about the skin deformations and stresses.

\subsection{Geometrical Behaviour}

Given the characteristics of the biological tissue, the skin can be considered as a deformable solid [22]. The mayor characteristic of an elastic tissue is its reversibility; if the applied forces are suppressed, the body returns to its original state [20,21].

The acting forces in the incision deform skin and tissues, and, when the forces are suppressed, the skin comes back to its original state as an elastic body. The elasticity of the skin generates a relation between forces and strains given by Equation (1):

$$
\sigma=\frac{F}{A}
$$

where $\mathrm{F}$ is the force and $\mathrm{A}$ is the area [20].

If the acting force $\Delta F$ on a part of area $\Delta A$ the stress as a vector is defined in one point. The strain tensor in a point can be defined for the orientation by means of the Cauchy Equation (7).

$$
\bar{t}_{n}=\underline{T} \cdot \bar{n}
$$

where $\bar{t}_{n}$ is the strain vector associated, and $\underline{T}$ is the strain tensor [20].

This relations allows for graphing the results deformations and forces. 


\subsubsection{Mohr Circle}

The graphic representation of strain states are divided into the $x$-axis, which is the normal strain, and the $y$-axis is the maximal and minimal strain at the intersection in the circle $[20,21]$. The opening incision process consists of retracting tissues at a defined depth, and the main strains are simplified only in $\sigma_{x}$ and $\sigma_{y}$. The other points are discharged.

If the radius is defined by the retraction length, $\sigma_{y}$ can be found by Equation (3) in the $\left(\sigma_{x}, \sigma_{y}\right)$ coordinates [21]:

$$
R=\sqrt{\left(\frac{\sigma_{x}+\sigma_{y}}{2}\right)^{2}}
$$

If the acting force $\Delta F$ over an area $\Delta A$ is taken, the strain vector in a point can be defined:

$$
\bar{\sigma}=\sigma \cdot \bar{n}
$$

Then, the internal balance equations are reduced to:

$$
\begin{aligned}
& \frac{\delta \sigma_{x}}{\delta x}+f_{x}=0 \\
& \frac{\delta \sigma_{y}}{\delta y}+f_{y}=0 .
\end{aligned}
$$

\subsubsection{Lamé Ellipse}

When the tensional state is known in a point, the associated tension vector $t_{n}$ can be obtained. As the model take planar deformations with forces on one axis plane, the tensor strain can be written as [20,21]:

$$
\left(\begin{array}{c}
\tau_{x} \\
\tau_{y}
\end{array}\right)=\left(\begin{array}{cc}
\sigma_{x} & 0 \\
0 & \sigma_{y}
\end{array}\right) \cdot\left(\begin{array}{l}
n_{x} \\
n_{y}
\end{array}\right) .
$$

As $\bar{t}$ is parallel to $\bar{n}$, there are no tangential tensions and the plane and strain directions are denoted as principal. With this, the tensions are place on the axis $\left(t_{x}=x, t_{y}=y\right)[20,21]$.

$$
\left|\begin{array}{cc}
x & 0 \\
y & \sigma_{y}
\end{array}\right|^{2}+\left|\begin{array}{cc}
\sigma_{x} & x \\
0 & y
\end{array}\right|^{2}=\left|\begin{array}{cc}
\sigma_{x} & 0 \\
0 & \sigma_{y}
\end{array}\right|^{2}
$$

Equation (8) is the Lamé equation simplified into two dimensions, and, if the ellipse axis is aligned with the mayor axis, the equation can be simplified as shown below [21]:

$$
\left(\frac{x_{1}}{\sigma_{1}}\right)^{2}+\left(\frac{x_{2}}{\sigma_{2}}\right)^{2}=1
$$

\subsection{Case Study}

The acting forces in the retracted tissue behave as a flexible material with linear parameters. An incision with defined depth has a punctual assigned force varying the retraction length along its cutting line by the relation $\mathrm{P}(\mathrm{x}, \mathrm{F})$. The experimental forces resulting in Section 2.1 represent $P_{1}(0.5,18.88)$ and $P_{2}(0.75,25.26)$ and generate the following equation of a line:

$$
y=25.52 x+6.12
$$

With this forces, the punctual strains along the incision can be found. In Section 2, the four parameters measured in the experiment were defined. If the lengths are related to the ellipse's minor axis, then this will be the first Lamé circle in the incision. The incision cut was made always with a 2 
$\mathrm{cm}$ length, which represents the major axis. The incision with it mayor retraction length at $1 \mathrm{~cm}$ (minor axis) has an ellipse equation written as:

$$
\frac{x^{2}}{0.25}+\frac{y^{2}}{1}=1
$$

Equation (11) has its foci in points $(0, \pm 0.86)$ and it has a latus rectum value of $L R=0.5$. If one is inside the ellipse, the circles have a radius value of $L R / 2$, and the incision retracted for the three Mohr's circles will have a workspace area as in Figure 5.

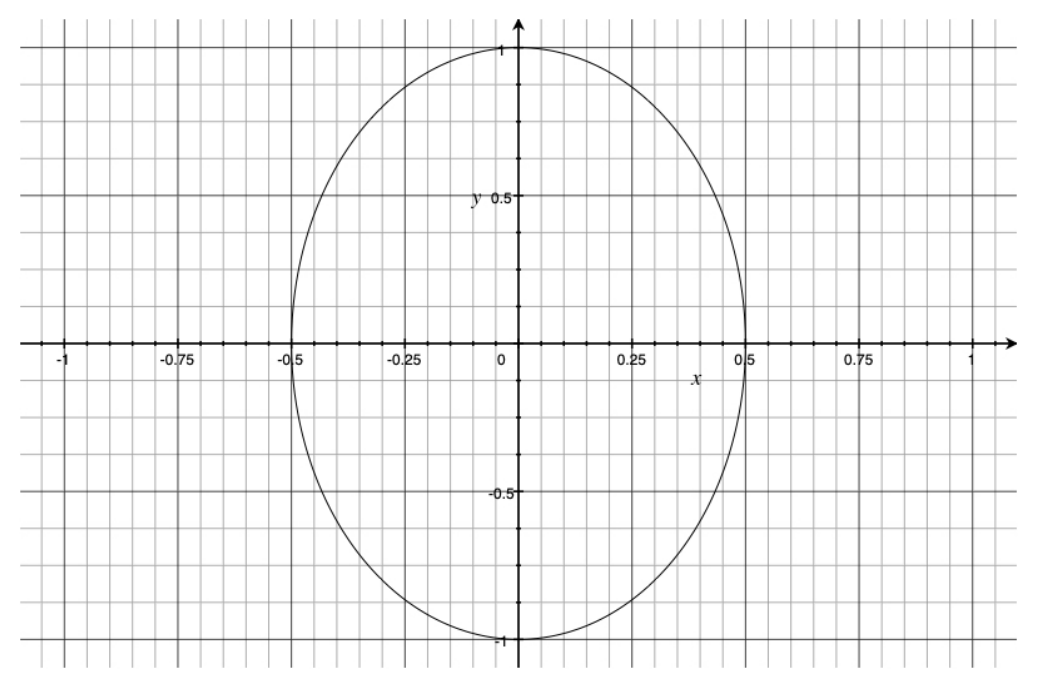

Figure 5. Workspace representation of Equation (11) planar incision retraction.

The circles $\left(C_{1}\right.$ and $\left.C_{3}\right)$, which have their origins on the two foci (Figure 5), have the circle equations shown in Equation (13).

$$
x^{2}+y^{2} \pm 1.72 y+0.676=0
$$

The remainder circle $\left(C_{2}\right)$, placed on the origin in Figure 5, has the following circle equation:

$$
x^{2}+y^{2}-0.25=0
$$

The Ellipse (Figure 5 ) has a symmetric form; therefore, the calculus can only be made on the positive part of the axis $x$.

The ellipse plotted by Equation (11) has a workspace area $\mathrm{A}=1.57 \mathrm{~cm}^{2}$, and the three circles do not have intersected areas and the value is $\mathrm{A}=1.50 \mathrm{~cm}^{2}$ (Figure 6). 


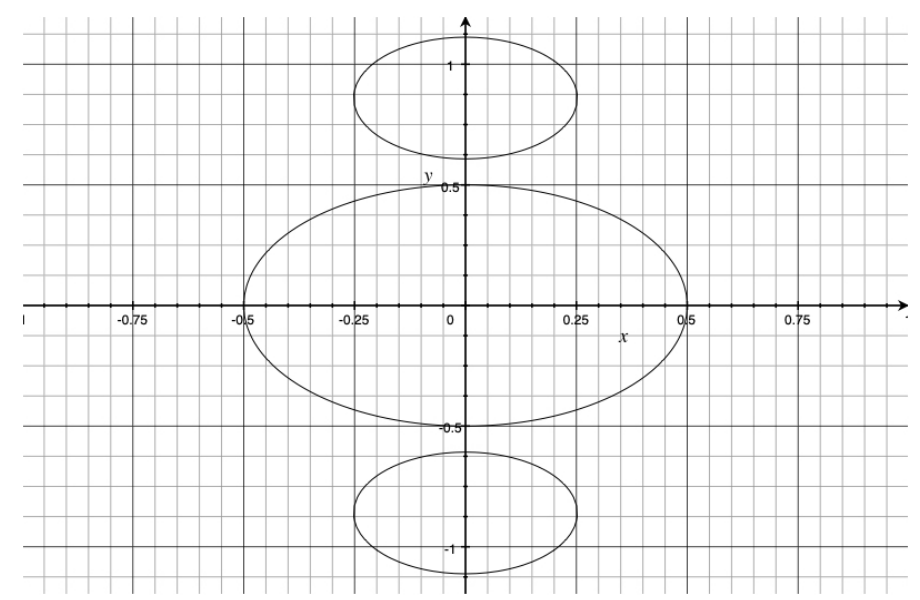

Figure 6. Workspace representation of the three circles with their punctual strains.

The volumetric workspace will change at different depths [23], Figure 7 shows a 3D representation of the incision retracted at a $1 \mathrm{~cm}$ maximal length.

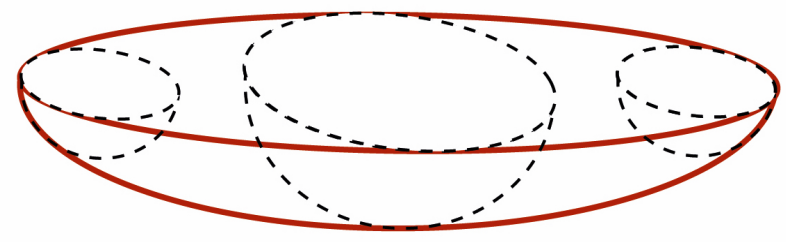

Figure 7. 3D representation of the incision retraction.

The punctual strain from circles $C_{1}$ and $C_{3}$ are placed in points $( \pm 0.25, \pm 0.86)$ and the strain value is $\sigma_{L R}=625,000 \mathrm{~N} / \mathrm{m}^{2}$. The punctual strain from circle $C_{2}$ has the value $\sigma_{c_{2}}=1,374,000 \mathrm{~N} / \mathrm{m}^{2}$. Figure 6 shows the punctual forces and strains from each circle. With the mathematical model, it is possible to have a theoretical incision replication if the retraction points has some considerations.

\subsection{Considerations}

If the retracted incision should have a homogeneous workspace area (Ellipse), the retraction points must have certain considerations. Figure 8 shows the incision of three retraction points.

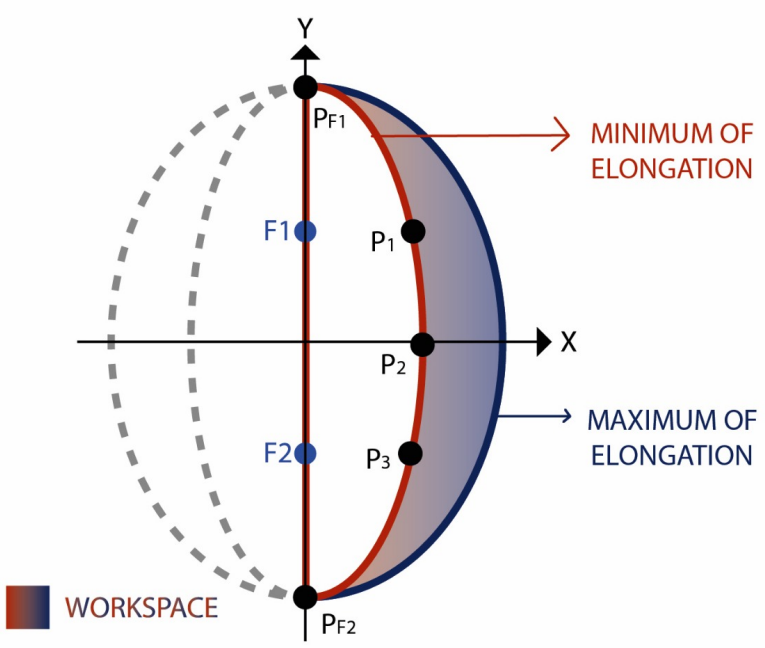

Figure 8. Geometrical incision behavior; the model has a symmetrical pattern. 
The retracted points in Figure 8 represent the maximum radius for each circle. The model considerations are listed below.

1. Each incision point has its maximum stretch and its minimum contraction (origin related).

2. The maximum stretch is related to the incision length (from $P_{F 1}$ to $P_{F 2}$ ). In the experimental process, all the incisions were made at $2 \mathrm{~cm}$.

3. The incision retraction points (Figure 8) are matched onto the ellipse line in the following form:

$$
\begin{aligned}
\frac{L R}{2} & =\overline{F_{1} P_{1}}=\overline{F_{2} P_{3}} \\
P_{F 1} & =V_{1} \\
P_{F 2} & =V_{2} \\
\text { Minoraxis } & =\overline{O P_{2}} .
\end{aligned}
$$

4. The retraction replicates an ellipse form, but it does not keep this geometry because the incision retracted has a workspace area tending to the radius or the major axis:

$$
\begin{aligned}
& 0<P_{1}<r \longrightarrow \text { Foci parallel }\left(F_{1}\right) \\
& 0<P_{2}<r \longrightarrow \text { Origin parallel }(O), \\
& 0<P_{3}<r \longrightarrow \text { Foci parallel }\left(F_{2}\right)
\end{aligned}
$$

5. The points' retraction independence will retract the tissue at the desired form, and it will have two possible stretch radii. Figures 9 and 10 exemplify this process.

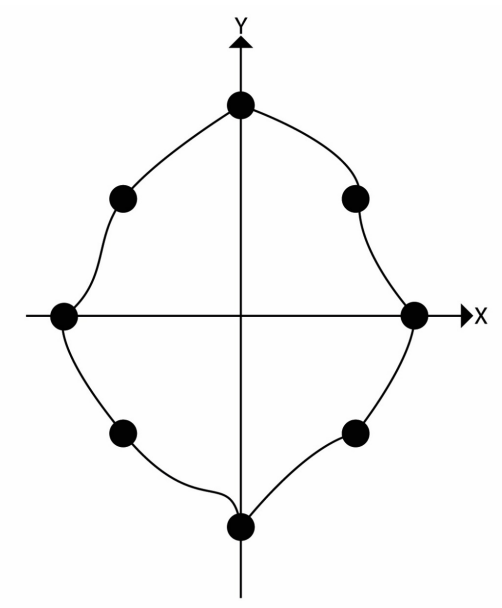

Figure 9. Outline of the model behavior in two dimensions. 


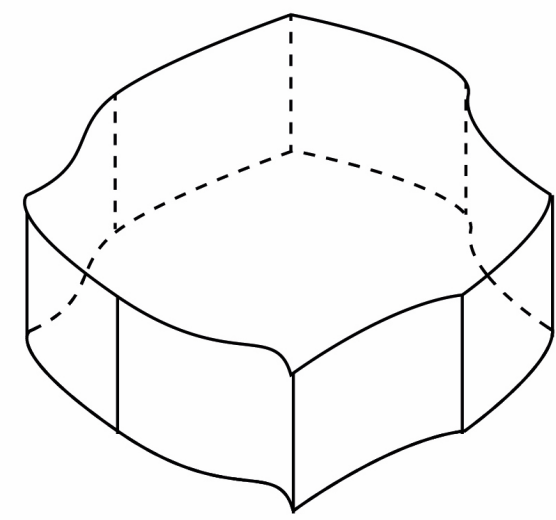

Figure 10. Outline of the model behavior in three dimensions.

\section{Validation}

The mathematical model shown in Section 2.3 is based on theoretical information and experimental information and, with these two, we can have both validations.

\subsection{Experimental validation}

The experimental part was made by replicating the skin retraction process in a pig's tissue. Given the force data obtained in Section 2.1, the validation stage consisted of retracting the incision on a desired force and then measuring the length that the skin was retracted. If a new pig's skin is retracted under the same conditions and the resulting forces measured are similar to the forces founded in Section 2.1, then the model is valid.

\subsubsection{Experimental Arrangement}

For this part, the pig's head had the characteristics shown in Table 4. The instruments used were the same as listed in Table 3, and the pig's head is located between the universal supports with the light placed in the incision origin.

Table 4. Dimensions, weights, and sample's age for the validation experiment.

\begin{tabular}{cc}
\hline \multicolumn{2}{c}{ Characteristics } \\
\hline Animal part & Pig's head \\
Age & 6 months \\
Animal's weight & $9 \mathrm{~kg}$ \\
Head's weight & $2 \mathrm{~kg}$ \\
& Long: 450 \\
Dimensions (mm) & width: 125 \\
& High: 115 \\
TIF certification & Yes \\
\hline
\end{tabular}

After the incision was made, it was retracted at the hook connected to the digital dynamometer. The data acquisition shows the measured force retracted. When the desired force is achieved, the resulting length was measured with a digital Vernier (IP67, series 0-150 mm, Mitutoyo Inc. Chicago, Illinois, EUA). This process was replicated four times. 


\subsubsection{Experimental Results}

The experimental validation is shown below. The measured data are power related needed to keep the incision retracted a desired length over the experiment. The experiment has its average values shown in Table 5.

Table 5. Test made for the experiment with 221 events.

\begin{tabular}{cccccccc}
\hline \multicolumn{7}{c}{ Forces in Each Test } \\
\hline Test & Average & Standard Deviation & Variance & Kurtosis & Median & Maximum & Minimum \\
\hline T1 & 13.74529 & 0.76547 & 0.58595 & -2.5806 & 13.52 & 15.1 & 12.69 \\
\hline T3 & 18.88036 & 0.96741 & 0.93588 & -3.2372 & 18.81 & 20.91 & 16.4 \\
\hline T4 & 25.26041 & 2.17057 & 4.71137 & -2.6636 & 24.55 & 31.05 & 20.45 \\
\hline
\end{tabular}

The retraction length at $1 \mathrm{~cm}$ and $2 \mathrm{~mm}$ of depth has an average variation related to the maximum value of $1.335 \mathrm{~N}$, which represents a percentage variation of $9.8 \%$. The three forces measured (Figure 11) have the same statistical characteristics in time and measurements.

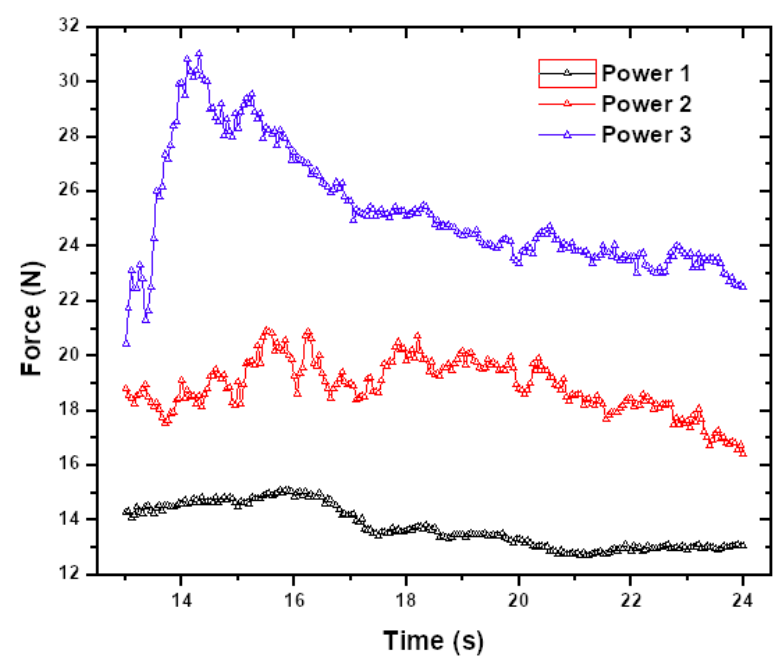

Figure 11. Lorentz adjustment for the experimental test for the average of all the forces.

In Table 6, the average data are listed. The information shows the minimal and maximal forces measured and it can be defined as the RRS tolerances.

Table 6. Tests performed.

\begin{tabular}{cccccccc}
\hline \multicolumn{7}{c}{ Average Forces from Three Test } \\
\hline Total Events & Average & Standard Deviation & Variance & Kurtosis & Median & Maximum & Minimum \\
\hline 221 & 19.29535 & 1.10309 & 1.2168 & -2.6835 & 19.17 & 21.4066 & 17.3166 \\
\hline
\end{tabular}

In Section 2.3, the mathematical model simplified the parameters that the RRS needs for its design. The RRS is related with forces and strains and is shown in Table 7. 
Table 7. Variables related to the experimental forces measured.

\begin{tabular}{ccccc}
\hline \multicolumn{2}{c}{ Requirements } & \multicolumn{3}{c}{ Strains $\mathbf{( x , y )}$} \\
\hline Area 1 & $0.00001 \mathrm{~m}$ & $\sigma_{1}$ & $1,374,000$ & $-1,373,999.986$ \\
Area 2 & $0.00002 \mathrm{~m}$ & $\sigma_{2}$ & 944,000 & $-943,999.9859$ \\
\hline Force 1 & $13.74 \mathrm{~N}$ & $\sigma_{3}$ & $1,263,000$ & $-1,262,999.979$ \\
\hline Force 2 & & & $18.88 \mathrm{~N}$ & \\
Force 3 & & & $25.26 \mathrm{~N}$ & \\
\hline
\end{tabular}

The forces measured in Table 7 are compared with the validation experiment. Table 8 shows the lengths measured after the incision was retracted at a normal force.

Table 8. Variables related to the experimental forces measured.

\begin{tabular}{ccc}
\hline Incision Force Retraction (Length-Depth) & Experiment $\mathbf{1}$ & Experiments 2 \\
\hline $13.74 \mathrm{~N}(1 \mathrm{~cm}-2 \mathrm{~mm})$ & $1.28 \mathrm{~cm}$ & $1.02 \mathrm{~cm}$ \\
\hline $18.88 \mathrm{~N}(1 \mathrm{~cm}-4 \mathrm{~mm})$ & $1.2 \mathrm{~cm}$ & $1.14 \mathrm{~cm}$ \\
\hline $25.26 \mathrm{~N}(1.5 \mathrm{~cm}-4 \mathrm{~mm})$ & $1.41 \mathrm{~cm}$ & $1.62 \mathrm{~cm}$ \\
\hline
\end{tabular}

The experimental validation gives similar length values for each incision retracted; therefore, the experimental part corroborates the incision model and the design specifications founded through it.

\subsection{Theoretical Validation}

As the model presented in Section 2.3 is based on theoretical models of human skin, Its theoretical validation consists of replicating the incision retraction. With strains and forces, the Lamé tensor can be plotted in different dimensions as Figures 12 and 13 show.

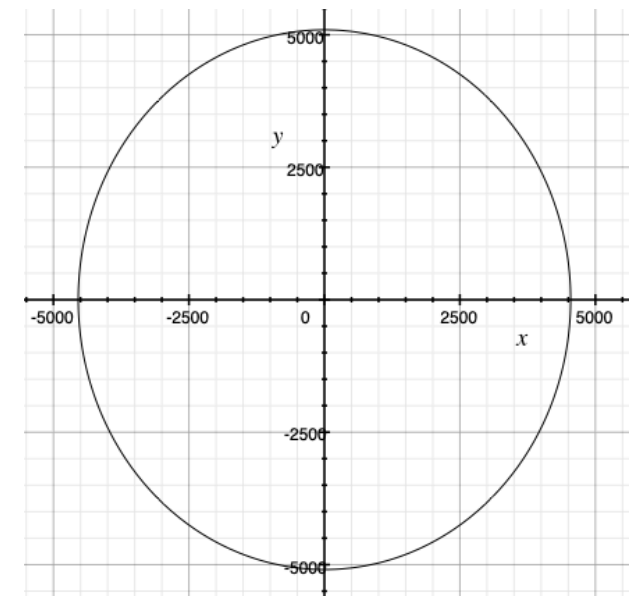

Figure 12. Outline of the model behavior in 2 dimensions. 


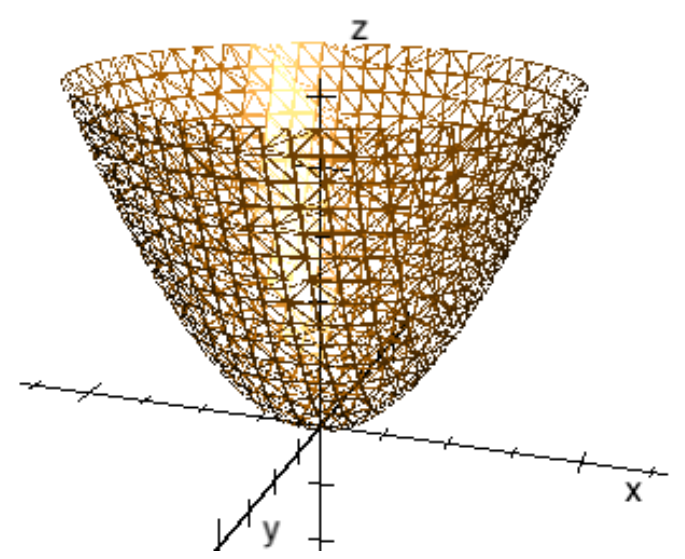

Figure 13. Outline of the model behavior in three dimensions plotted from Equation (14).

Figures 12 and 13 represent the incision strain at a desired area incision retraction for all possible depths. Equation (14) shows the mathematical behavior:

$$
\left(\frac{x}{503466.66}\right)^{2}+\left(\frac{y}{632800}\right)^{2}-z=1 .
$$

This theoretical model can replicate the incision retraction process which can be the first theoretical validation.

\section{Computational Software}

The mathematical analysis is known as the Finite Element Method (FEM), which is a numerical method for solving problems in mathematical physics [24]. A mathematical software that solves partial differential equations is known as FreeFem++. It has been developed by the Laboratoire Jacques-Louis Lions and the software has its own code for the Lamé Ellipse [25]. If FreeFem++ is run four times with different positions of strain, the incision retraction simulation can be found (Figure 14).

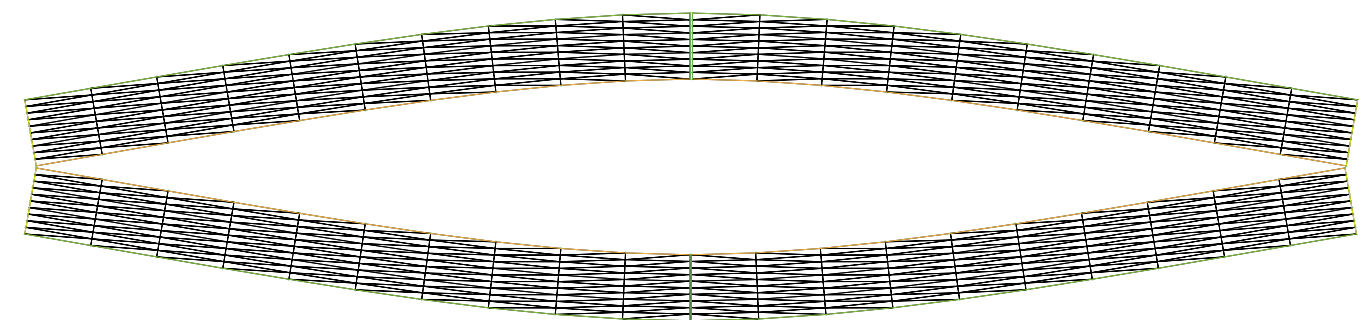

Figure 14. Incision retraction simulation with FreeFeem++ software.

FreeFem++ is an independent software that uses the same tensor theories that the mathematical model made in this article uses. Figure 14 replicates the same behaviors shown in Equation (14).

With the model validation, then the data obtained can be considered as a good approximation of the design specifications for a Retractor Robotic System.

\subsection{Design Specifications}

The mathematical model has tensions exemplified in Equation (15). The tensor represents the three-dimensional strain behavior of the incision while it is retracted.

$$
T_{1}=\left(\begin{array}{ccc}
1374000 & 0 & 0 \\
0 & -1373999.986 & 0 \\
0 & 0 & 0.00636
\end{array}\right) ; \quad T_{3}=\left(\begin{array}{ccc}
944000 & 0 & 0 \\
0 & -943999.9859 & 0 \\
0 & 0 & 0.00645
\end{array}\right)
$$




$$
T_{2}=\left(\begin{array}{ccc}
1263000 & 0 & 0 \\
0 & -1262999.979 & 0 \\
0 & 0 & 0.00954
\end{array}\right) .
$$

The mathematical model gives the Design Specifications listed in Table 9.

Table 9. Design specifications.

\begin{tabular}{ccc}
\hline Figure & Area $\left.\mathbf{( c m}^{\mathbf{2}}\right)$ & Pressure $\mathbf{( P a )}$ \\
\hline Superior Part & 3.141 & $43,735.7$ \\
\hline Inferior Part & 7.068 & $26,709.7$ \\
\hline Workspace & $9.424_{-0}^{+1}$ & $26,801.6$ \\
\hline
\end{tabular}

The main problem was simplified from an unknown parameter in three dimensions into a two-dimensional model in relation to forces and strains.

\section{Discussion}

This design specifications allows us to build a Robotic Retractor System. The model should be adapted for a selected actuator. The actuator will define the retraction points needed for a homogeneous workspace area and, with that, the mathematical model presented in this article can define the design specifications for this particular actuator.

\section{Conclusions}

This article can be divided into experimental and theoretical conclusions. Each of these conclusions are listed below. It is important to mention that Figure 13 represents the schematic patent developed for the mathematical incision retraction process.

\subsection{Experimental Conclusions}

- The force-retraction effects are related to the incision type, the points retraction number, and the incision location. These effects are factors that alter the deformation and the skin behavior

- From the experiment, it can be inferred that skin tends to be more stable through time. The RRS tolerances can be defined with the media and maximum values of the experiment.

- The skin retraction can be inferred as a scalable process related to forces and lengths.

- For a homogeneous workspace, the retraction process must have at least six retraction points. The simplest skin retracted geometrical form is an Ellipse.

\subsection{Theoretical Conclusions}

- The mathematical model requires, as input, to know the systems' forces and lengths in the retraction process; then, it will compute the system strains and resulting areas.

- The mathematical model and the design specifications are valid when the skin retracted behaves as a flexible body.

- The strain system will behave as the model predicts. If the incision retraction points are mobiles, the workspace area will be almost the same in all of the procedures.

- If the stretching length is increased, the incision length will decrease.

- The mathematical model behaves as the Robotic Retractor System requires. It is assumed that the actuator for the RRS will replicate the retraction process model with the tolerances founded in the experimental part.

- With the measures obtained, it is possible to build a Robotic Retractor System. 
The experimental and theoretical results are consistent with the theoretical review and define the minimal six points for a homogeneous retraction. The experiment and the theory allow for building a Robotic Retractor System depending a selected actuator.

\section{Patents}

The presented mathematical model generates a device patented in the Mexican Institute of Industrial Property (IMPI) named Patent of a calibrator device of ocular surgery retraction, and it has the registration number MX/F/2019/003098.

Author Contributions: V.O.R.-B. developed the practical aspects of this research, created the mathematical model, and wrote the first draft of this paper, L.A.Z.-A. provided the initial formulation of the methodology and did exhaustive work on reviewing and editing. R.M.V.-R., J.J.R.-L., and G.M.C.-M. supervised this research. All authors participated in the reviewing and writing of this manuscript. All authors have read and agreed to the published version of the manuscript.

Funding: This research was funded by CONACYT (Consejo Nacional de Ciencia y Tecnología) Grant No. 863564.

Acknowledgments: The authors would like to thank Ángel Nava Castañeda for all the support during the the lacrimal surgeries. The authors also would like to thank all of the patients for their help and effort during the research study in addition to the metrology lab staff at the UAEM for their assistance in the experimental period. The authors would especially like to thank Luz Maria Mendez for all of the assistance, tolerance, and the writing of the user satisfaction letter with the official date of 10 October 2019.

Conflicts of Interest: The authors declare that they have no conflict of interest.

\section{References}

1. Weber, R.K.; Keerl, R.; Schaefer, S.D.; Rocca, R.C. Atlas of Lacrimal Surgery; Springer Science \& Business Media: Berlin, Germany, 2007; Volume 10.

2. Ali, M.J. Principles and Practice of Lacrimal Surgery; Springer: Berlin, Germany, 2018.

3. Presutti, L.; Mattioli, F. (Eds.) Endoscopic Surgery of the Lacrimal Drainage System; Springer: Berlin, Germany, 2016.

4. Robles-Bringas, A.; del Ángel-Arenas, M.T.; Bustamante-Domínguez, G. Experiencia en cirugía para dacriocistitis en el Hospital General de México. Rev. Mex. De Oftalmol. 2009, 83, 293-295.

5. Vidas, O.L.C.S.S. Alianza Mundial para la Seguridad del Paciente. In Segundo Reto Mundial por la Seguridad del Paciente; Organización Mundial de la Salud, 2008. Available online: https:/ /www.who.int/patientsafety/ information_centre/documents/ps_research_brochure_es.pdf (accessed on 13 January 2020).

6. Vishwakarma, R.; Singh, N.; Ghosh, R. A study of 272 cases of endoscopic dacryocystorhinostomy. Indian J. Otolaryngol. Head Neck Surg. 2004, 56, 259-261. [PubMed]

7. Fine, I.H.; Mojon, D.S. (Eds.) Minimally Invasive Ophthalmic Surgery; Springer: Berlin, Germany, 2010.

8. Deshpande, S.; Agashe, A.; Loomba, A.; Dhiware, N. Step-by-step dacryocystorhinostomy for beginners: An expert's view. J. Clin. Ophthalmol. Res. 2014, 2, 161.

9. Ali, M.J.; Naik, M.N.; Honavar, S.G. External dacryocystorhinostomy: Tips and tricks. Oman J. Ophthalmol. 2012, 5, 191. [CrossRef] [PubMed]

10. Sundaram, V.; Barsam, A.; Barker, L.; Khaw, P.T. Training in Ophthalmology; Oxford University Press: Oxford, UK, 2016.

11. Metson, R.; Woog, J.J.; Puliafito, C.A. Endoscopic laser dacryocystorhinostomy. Laryngoscope 1994, 104, 269-274. [CrossRef] [PubMed]

12. Junceda-Moreno, J.; Dos-Santos-Bernardo, V.; Suárez-Suárez, E. Técnica de doble intubación para el tratamiento de la epífora en casos complicados. Arch. De La Soc. Espa Nola De Oftalmol. 2006, 81, 101-106. [CrossRef] [PubMed]

13. Benatar-Haserfaty, J.; Monleón de la Calle, M.; Sanz-López, A.; Muriel García, A. Dacriocistorrinostomía externa realizada en el consultorio bajo anestesia locorregional y sedación. Rev. Espa Nola De Anestesiol. Y Reanim. 2007, 54, 23-28.

14. Netzlaff, F.; Schaefer, U.F.; Lehr, C.M.; Meiers, P.; Stahl, J.; Kietzmann, M.; Niedorf, F. Comparison of bovine udder skin with human and porcine skin in percutaneous permeation experiments. Altern. Lab. Anim. ATLA 2006, 34, 499-513. [PubMed] 
15. Schmook, F.P.; Meingassner, J.G.; Billich, A. Comparison of human skin or epidermis models with human and animal skin in in-vitro percutaneous absorption. Int. J. Pharm. 2001, 215, 51-56. [CrossRef]

16. García Sánchez, J.; Aguilera Terrats, J.R.; Castillo Rosas, A. Guía técnica para la construcción de escalas de actitud. Revista electrónica de pedagogía 2011.

17. Matas, A. Diseño del formato de escalas tipo Likert: Un estado de la cuestión. Rev. Electrónica De Investig. Educ. 2018, 20, 38-47. [CrossRef]

18. Joodaki, H.; Panzer, M.B. Skin mechanical properties and modeling: A review. Proc. Inst. Mech. Eng. Part H: J. Eng. Med. 2018, 232, 323-343. [CrossRef] [PubMed]

19. Benner, D.C.; Rinsland, C.P.; Devi, V.M.; Smith, M.A.H.; Atkins, D. A multispectrum nonlinear least squares fitting technique. J. Quant. Spectrosc. Radiat. Transf. 1995, 53, 705-721. [CrossRef]

20. Linero, D.L. Elementos de la Mecánica del Medio Continuo para Cuerpos Sólidos; University Nacional de Colombia: Bogotá, Colombia, 2010.

21. Olivella, X.O.; de Saracíbar Bosch, C.A. Mecánica de Medios Continuos para Ingenieros; University Politèc. de Catalunya: Barcelona, España, 2002; Volume 92.

22. CHAVES, E.W.V. Mecánica del medio continuo. In Modelos Constitutivos; CIMNE: Barcelona, Spain, 2014; pp. 978-984.

23. Cavas-Martínez, F.; Piñero, D.; Fernández-Pacheco, D.; Mira, J.; Cañavate, F.; Alió, J. Assessment of Pattern and Shape Symmetry of Bilateral Normal Corneas by Scheimpflug Technology. Symmetry 2018, 10, 453. [CrossRef]

24. Font, R.; Peria, F. The Finite Element Method with FreeFem++ for beginners. Electron. J. Math. Technol. $2013,7$.

25. Hecht, F.; Pironneau, O.; Le Hyaric, A.; Ohtsuka, K. FreeFem++ Manual, 2005. Available online: https://web.math.pmf.unizg.hr/nastava/ppm2/manual-full.pdf (accessed on 13 January 2020).

(C) 2020 by the authors. Licensee MDPI, Basel, Switzerland. This article is an open access article distributed under the terms and conditions of the Creative Commons Attribution (CC BY) license (http:/ / creativecommons.org/licenses/by/4.0/). 